\title{
A MATHEMATICAL MODEL OF POWDER COMPONENTS OXIDATION DURING THERMAL SPRAY PROCESS
}

\author{
Kossenko A., Lugovskoy Alex, Zinigrad M. \\ College of Judea and Samaria, Ariel, Israel
}

\begin{abstract}
A model developed on the base of kinetic principles of mass transfer allows performing computer simulation of the oxidation of powder materials during the thermal spray process. Such simulation enables one to determine the oxidation degree of the powder. The calculation is based on determining quasi-stationary oxygen diffusion flow on a flying particle. Calculations performed for various spray powders and various flammable gases demonstrate a significant decrease of the oxidation degree with the growth of the particles diameter and density of a spray powder. The calculation results were confirmed by experiments.
\end{abstract}

\section{Introduction.}

Intensive oxidation of a spray powder occurs in the course of the thermal spray and particularly of the flame spray processes $[1,2]$ causing the formation of oxide film on the particles when these hit the base material surface. For instance, the oxidation of components of nickel self-fluxing powder is described with the following reaction equations:

$$
\begin{gathered}
2 \mathrm{Ni}+\mathrm{O}_{2} \rightarrow 2 \mathrm{NiO} \\
\mathrm{Ti}+\mathrm{O}_{2} \rightarrow \mathrm{TiO}_{2} \\
\mathrm{Si}+\mathrm{O}_{2} \rightarrow \mathrm{SiO}_{2} \\
4 /{ }_{3} \mathrm{~B}+\mathrm{O}_{2} \rightarrow{ }^{2} /{ }_{3} \mathrm{~B}_{2} \mathrm{O}_{3} \\
2 \mathrm{C}+\mathrm{O}_{2} \rightarrow 2 \mathrm{CO} \\
4 /{ }_{3} \mathrm{Fe}+\mathrm{O}_{2} \rightarrow{ }^{2} /{ }_{3} \mathrm{Fe}_{2} \mathrm{O}_{3}
\end{gathered}
$$

These reactions cause changes of the spray material composition and deterioration of the coating properties [3]. The lack of experimental data in the literature prevents one from determining the dependence of the oxidation process on technological spray parameters and formulating recommendations on the lowering of the interaction of a spray powder with oxygen. Gershenson and Boronenkov [4] calculated the oxide contents in the slag film, which is formed on the coating surface during the plasma-spray process. Their calculations provide the equilibrium contents of the oxide film in contact with the coating material, but not any quantitative estimate of the oxygen content in the coating, because the coating to film mass ratio is unknown.

Therefore, it is not possible to calculate the content of oxygen in an obtained coating, the burn-out losses of the powder components and thus to forecast the result of a thermal spray process.

An assumption was made [5] that the oxidation process is controlled by the step of oxygen diffusion in a gas stream. It is based on the fact that the interaction time of a particle with the gas flow is significantly longer than the time for the formation of a diffusion layer when a practically constant concentration gradient is achieved.

Another assumption, which considerably simplifies the calculations without a considerable increase of error, is that of oxygen mass-transfer being quasi-stationary. Therefore, the calculation of the oxidation depth of powder particles can be reduced to the calculation of the diffusion flow of oxygen towards a flying particle. 


\section{Calculation algorithm}

Taking into consideration the assumptions about gas diffusion being the ratedetermining step and the mass transfer process being quasi-stationary, the oxidation depth ( $\psi$, mass percent) equals the number of moles of oxygen $\mathrm{Q}_{\mathrm{O}}$, which has diffused to a spherical particle having mass $m[6]$ :

$$
\psi=\frac{Q_{O}}{m} 100=\frac{100}{m} \int_{0}^{\tau} j S d \tau=\frac{600}{\rho d} \int_{0}^{l} \frac{j}{V} d l,
$$

where $\rho, V$ are the density and velocity of the particle, $l$ is the distance of the nozzle edge to the item being treated. By expressing specific diffusion flow $j$ as:

$$
j=K^{D} C_{O}=N u \frac{D}{d} C_{O}
$$

the basic equation for calculation of the oxidation depth for a particle having given mass and diameter is obtained:

$$
\psi=\frac{600}{\rho d^{2}} \int \frac{N u D C_{O}}{V} d l
$$

where $\mathrm{Nu}$ is Nusselt number, $\mathrm{D}$ is the oxygen diffusion coefficient in the combustion products mixture сгорания, $\rho, d, V$ are the density, diameter and velocity of the particle and $\mathrm{C}_{\mathrm{O}}$ is the oxygen concentration in the gas:

$$
C_{O}=\frac{P_{O_{2}} M}{R T}=3.9 \frac{P_{O_{2}}}{T_{g i}},\left[\mathrm{~g} / \mathrm{m}^{3}\right]
$$

In analogy to plasma spray the value of the oxygen pressure in the combustion products stream $P_{O_{2}}$ according to experimental data $[1,7]$ is accepted (to $5 \%$ ) as:

$$
\mathrm{Po}_{2}=0,048^{*} 10^{5}\left(l-l_{\mathrm{c}}\right)^{0,3}[\Pi \mathrm{\Pi a}]
$$

where $l_{\mathrm{c}}$ is the length of the stream core, $\mathrm{mm}$, which is found by solving the equation for the gas velocity after the assumption about the gas velocity in the core stream being constant and equal to $\mathrm{V}_{\mathrm{g}}^{0}$.

The particle velocity on a given trajectory length $\Delta l_{\mathrm{i}}$ is fetermined from the expression [8]:

$$
V_{i}=V_{g_{i}}\left(1-\frac{V_{g_{i}}-V_{i-1}}{V_{g_{i}}\left(1+\sqrt{2 K_{D} \Delta l_{i}\left(V_{g_{i}}-V_{i-1}\right)^{-0.6}}\right)}\right)
$$

$K_{D}=12.75 \frac{\rho_{g}^{0.4} \mu_{g}^{0.6}}{d^{1.6} \rho}, \mu_{\mathrm{g}}$ and $\rho_{\mathrm{g}}$ are the viscosity and density of the gas.

The temperature $\left(T_{g i}\right)$ and gas velocity $\left(V_{g i}\right)$ distributions in the burner torch are found for the internal zone I (fuel and combustion products) and the external zone II (oxidizer and combustion products) according the following formulae [11]:

$$
\begin{gathered}
\mathrm{I}-\frac{u}{u_{0}}=\frac{\left(1-w_{I}\right) F_{I}}{2}\left[1+\sqrt{1+4 \frac{w_{I}}{\left(1-w_{I}\right)^{2}} \frac{F}{F_{I}^{2}}}\right], \\
\mathrm{II}-\frac{u}{u_{0}}=\sqrt{w_{I}} \frac{w_{I I}-1}{2 w_{I I}} F_{I I} \sqrt{F_{f}}\left[1+\sqrt{1+4 \frac{w_{I I}}{\left(1-w_{I I}\right)^{2}} \frac{F}{F_{f} F_{I I}^{2}}}\right],
\end{gathered}
$$




$$
\begin{gathered}
\mathrm{I}-\frac{T-T_{0}}{T_{f}-T_{0}}=1-\frac{F_{I}}{\rho u}(\rho u)_{0}, \\
\mathrm{II}-\frac{T-T_{\infty}}{T_{f}-T_{\infty}}=\sqrt{\frac{F_{f}}{w_{I}}} \frac{F_{I I}}{\rho u}\left(\rho u_{0}\right),
\end{gathered}
$$

where $F=P(\xi, y), F_{f}=P\left(\xi_{f}, y_{f}\right), F_{I}=1-\frac{1-P(\xi, y)}{1-P\left(\xi_{f}, y_{f}\right)}, F_{I I}=\frac{P(\xi, y)}{P\left(\xi_{f}, y_{f}\right)}, P(\xi, y)$ is an empiric P-function of coordinates $(x, y)$. Along the torch axis P-function becomes:

$$
P(\xi, 0)=1-\exp \left(-\frac{1}{4 \xi}\right)
$$

The values of this P-function are given in tables [10].

Using the dependence of combustion products viscosity $\mu$ on the temperature [11], the values of $\mathrm{V}_{\mathrm{g}}{ }^{0}, \mathrm{~T}_{\mathrm{g}}{ }^{0}, d_{\mathrm{c}}, \rho$, and equations (4)-(9), the oxidation depth $\psi$ of a powder particle having diameter $d$ can be found by the integration of equation (3).

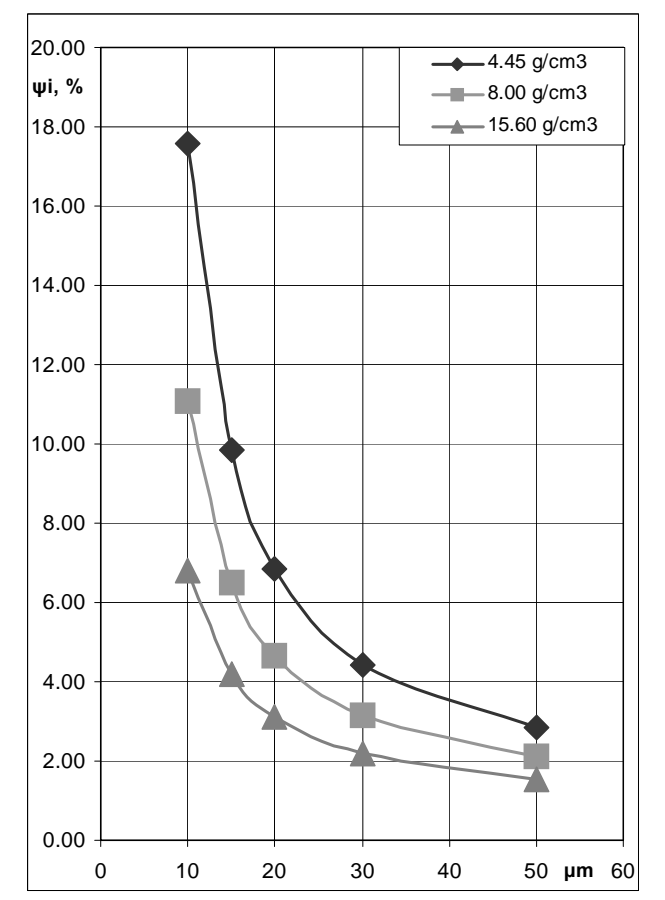

Fig. 1. Dependence of the oxidation degree on powder density and dispersion.

\section{Calculations}

Equations (3) - (9) present the mathematical model of the oxidation of powder components during gas-flame spray process. An algorithm for their solution was developed and realized in a MS Excel-based program.

The program allows calculating the oxidation degree (i.e. the total amount of oxygen delivered to a particle) of the powder and the velocity of particles of the spray material as functions of various technological parameters, viz.:

- Granulometric composition and density of a spray material;

- Fuel gas type $\left(\mathrm{C}_{2} \mathrm{H}_{2}, \mathrm{CH}_{4}, \mathrm{C}_{3} \mathrm{H}_{8}\right.$, $\left.\mathrm{C}_{4} \mathrm{H}_{10}, \mathrm{H}_{2}\right)$, its consumption and temperature and those of oxygen in the course of the spray process;

- Spray distance.

- Technological parameters of the gas burner (nozzle diameter, pressure and temperature of the surrounding air;

Calculations were performed for various materials, fuel gases $\left(\mathrm{C}_{2} \mathrm{H}_{2}, \mathrm{CH}_{4}, \mathrm{H}_{2}\right)$ and spray distances $(50-300 \mathrm{~mm})$.

The initial flame velocity for the mixture of acetylene $(10 \mathrm{~L} / \mathrm{min}$ flow capacity) with oxygen (10 L / min flow capacity), standard METCO type 5P burner, P-7G nozzle with $100.8 \mathrm{~mm}$ ID holes is $264 \mathrm{~m} / \mathrm{sec}$.

The results of the oxidation degree calculations for $\mathrm{Ni}$ alloy, titanium boride and tungsten carbide (densities: $8.0,4.45,15.6 \mathrm{~g} / \mathrm{cm}^{3}$ respectively) for the powder 
particles sizes $10,15,20,30,50 \mu \mathrm{m}$ and the spray distance of $150 \mathrm{~mm}$ are given in Fig. 1.

\section{Experimental}

Because of relatively low temperatures of the gas stream occurring during gasflame spray (unlike those during plasma spray) no powder dispersion occurs $[1,7]$. Therefore, the particles hitting the base material have the initial granulometric composition.

Sprayed coatings by nickel self-fluxing powder (Ni-Cr-B-Si), titanium and tungsten carbide were obtained. The determination of oxygen amount in the coatings was performed by vacuum melting on LECO TC-436 analyzer. The results of the analyses are given in Table 1.

In order to have the calculation results compared to the experiment, the oxidation degree $\psi_{\mathrm{c}}$ was determined as:

$$
\psi_{\mathrm{c}}=\Sigma \psi_{\mathrm{i}} \mathrm{P}_{\mathrm{i}}
$$

where $\psi_{\mathrm{i}}$ is the oxidation degree of powder particles of a given diameter as is determined from the figure $1, \mathrm{P}_{\mathrm{i}}$ is the mass fraction of powder particles having mean diameter $d_{i}$.

The calculated values are in reasonable accordance with the experiment (Table 1), thus confirming the relevancy of the assumptions and the calculation algorithm. The calculated values being somewhat higher than the experimental, can be caused by a larger oxidation degree of particles moving along the periphery of the burner torch, where the velocity and the temperature of particles are lower and the oxygen concentration is higher. The difference between the calculated $\psi$ and the experimental $\psi_{\mathrm{c}}$ observed for the spray distance shorter than $100 \mathrm{~mm}$ (experiment 4 in Table 1) might be caused by the higher turbulence of the stream and the increase of oxygen contents in it as well as by the lengthening of the thermal cycle of particle crystallization on the substrate. For the case of tungsten carbide the difference can also be caused by the formation of volatile carbon oxides. The decisive influence of the particle diameters on the value of oxidation degree is confirmed by experiments 7 and 8 (Table 1), viz. the coarser powder grains the poorer the oxidation.

Table 1. Calculated and experimental oxidation

\begin{tabular}{|c|c|c|c|c|c|c|c|c|c|c|c|c|c|}
\hline \multirow{3}{*}{ 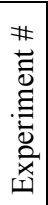 } & \multirow{3}{*}{$\begin{array}{l}\frac{\pi}{\overrightarrow{0}} \\
\frac{\overrightarrow{0}}{\pi} \\
\sum\end{array}$} & \multirow{3}{*}{ 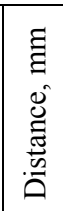 } & \multicolumn{3}{|c|}{ Flame } & \multicolumn{5}{|c|}{$\begin{array}{c}\text { Fraction, mass } \% \text {, of particles } \\
\text { of diameter, } \mu \mathrm{m}\end{array}$} & \multicolumn{3}{|c|}{ Oxygen contents, mass $\%$} \\
\hline & & & \multirow[b]{2}{*}{ Fuel } & \multirow{2}{*}{$\begin{array}{c}\text { Fuel } \\
\text { consump- } \\
\text { tion, 1/min }\end{array}$} & \multirow{2}{*}{$\begin{array}{c}\mathrm{O}_{2} \\
\text { consump- } \\
\text { tion, } 1 / \mathrm{min}\end{array}$} & \multirow[b]{2}{*}{$<10$} & \multirow[b]{2}{*}{$10-20$} & \multirow[b]{2}{*}{$20-30$} & \multirow[b]{2}{*}{$30-40$} & \multirow[b]{2}{*}{$40-50$} & \multicolumn{2}{|c|}{ Experiment } & \multirow[b]{2}{*}{ Calculation } \\
\hline & & & & & & & & & & & Range & Average & \\
\hline 1 & \multirow{3}{*}{$\mathrm{Ti}$} & 150 & $\mathrm{C}_{2} \mathrm{H}_{2}$ & 8.2 & 8.2 & 3.3 & 30.9 & 65.8 & - & - & $9.0-10.5$ & 9.75 & 9.12 \\
\hline 2 & & 150 & $\mathrm{C}_{2} \mathrm{H}_{2}$ & 12.3 & 12.3 & 3.3 & 30.9 & 65.8 & - & - & $5.7-8.2$ & 6.95 & 7.3 \\
\hline 3 & & 220 & $\mathrm{C}_{2} \mathrm{H}_{2}$ & 8.2 & 8.2 & 3.3 & 30.9 & 65.8 & - & - & $10.9-14.0$ & 12.45 & 12.35 \\
\hline 4 & \multirow{6}{*}{$\mathrm{Ni}$} & 50 & $\mathrm{C}_{2} \mathrm{H}_{2}$ & 8.2 & 8.2 & 4.2 & 4.7 & 31.6 & 29.8 & 29.7 & $3.0-4.9$ & 3.95 & 2.26 \\
\hline 5 & & 100 & $\mathrm{C}_{2} \mathrm{H}_{2}$ & 8.2 & 8.2 & 4.2 & 4.7 & 31.6 & 29.8 & 29.7 & $2.5-5.3$ & 3.9 & 3.55 \\
\hline 6 & & 150 & $\mathrm{C}_{2} \mathrm{H}_{2}$ & 8.2 & 8.2 & 4.2 & 4.7 & 31.6 & 29.8 & 29.7 & $2.5-7.7$ & 5.1 & 4.99 \\
\hline 7 & & 150 & $\mathrm{C}_{2} \mathrm{H}_{2}$ & 8.2 & 8.2 & - & 100 & - & - & - & $6.5-10.0$ & 8.25 & 7.12 \\
\hline 8 & & 150 & $\mathrm{C}_{2} \mathrm{H}_{2}$ & 8.2 & 8.2 & - & - & - & 100 & - & $1.9-4.0$ & 2.95 & 2.63 \\
\hline 9 & & 150 & $\mathrm{C}_{2} \mathrm{H}_{2}$ & 12.3 & 12.3 & 4.2 & 4.7 & 31.6 & 29.8 & 29.7 & $3.2-4.4$ & 3.8 & 3.52 \\
\hline 10 & \multirow{2}{*}{ WC } & 100 & $\mathrm{C}_{2} \mathrm{H}_{2}$ & 8.2 & 8.2 & 0 & 4.4 & 8.5 & 41.2 & 45.9 & 0.8-0.9 & 0.85 & 1.73 \\
\hline 11 & & 150 & $\mathrm{C}_{2} \mathrm{H}_{2}$ & 8.2 & 8.2 & 0 & 4.4 & 8.5 & 41.2 & 45.9 & н.Д. & н.Д. & 2.19 \\
\hline
\end{tabular}




\section{Conclusions}

A mathematical model of the powder components oxidation in the process of gas-flame spray was developed. The quasi-stationary oxygen diffusion in the gas stream being the limiting stage of the powder oxidation was demonstrated on the base of the model and confirmed by the experiments. The main factors influencing the oxidation degree of the sprayed material are dispersion (particle surface area to volume ratio) and density (amount of oxygen diffused to the particle to the particle's mass ratio). As the fuel gas flow increases, the oxidation degree decreases due to the increase of the gas stream velocity and shortening of time for the particle staying in the stream.

The developed program enables one to evaluate the oxidation degree of a powder in the gas-flame thermal spray process for various fuel gases as a function of spray process parameters and sprayed materials and thus to forecast the properties of the obtained coating.

The results of the calculations are in a good agreement with the experiment.

\section{REFERENCES}

1. Thermal Spray Coatings: Research Design and Applications. Edited by Christopher C. Berndt. ASM International, 1993.

2. Hasui, A., Morigaki O. Hard-surfacing and thermal spray/transl. from Japanese by V. N. Popov, edit. By V. S. Stepin and N. G. Shesterkin., Moscow, Mashinostroyeniye, 1985.

3. Handbook of Thermal Spray Technology. Edited by J.R. Davis, Copublished by the Thermal Spray Society and ASM International, 2002.

4. Gershenson S. M., Boronenkov V. N., On the equilibrium composition of the oxide film formed during thermal spray and thermal treatment of $\mathrm{Ni}-\mathrm{Cr}-$ B-Si alloys. Izvestiya Vuzov, Tsvetnaya metallurgiya, 1978, 3, 89-92.

5. Gershenson S. M., Boronenkov V. N., Borisov Y. S. The oxidation kinetics of various materials in the plasma spray process. In "Theoretical Studies and practical applications of wearproof plasma coatings.", Ural Branch of the Academy of Sciences of the USSR, 1983, pp. 10-15.

6. D.A. Frank-Kamenetsky, Diffusion and heat transfer in chemical kinetics, $2^{\text {nd }}$ ed, Plenum Press, New York, 1969.

7. Hasui A., The technique of thermal spray, Moscow, Mashinostroyeniye, 1975.

8. $\quad$ Plasma Spraying. Edited by R. Suryanarayanan. World Scientific, 1993.

9. Griffiths John F., Barnard J. A. Flame and Combustion. CRC Press, 1995.

10. Masters J., Some application in physics of the P-function, The Journal of chemical Physics, v. 23, \# 10, 1955.

11. David R Lide, CRC, Handbook of Thermophysical and Thermochemical Data. CRC Press, 1994. 